\title{
Media Pembelajaran Matematika Materi Kombinatorika Berbasis Media Interaktif pada Siswa SMK
}

\author{
Ana Cholila ${ }^{1}$, Purwanto ${ }^{1}$, Erry Hidayanto ${ }^{1}$ \\ ${ }^{1}$ Pendidikan Matematika-Universitas Negeri Malang
}

\begin{tabular}{l}
\hline \hline INFO ARTIKEL \\
\hline Riwayat Artikel: \\
Diterima: 23-01-2019 \\
Disetujui: 25-04-2019 \\
\hline
\end{tabular}

\section{Kata kunci:}

learning media;

mathematics;

combinatorics;

interactive;

media pembelajaran;

matematika;

kombinatorika;

interaktif

\section{ABSTRAK}

Abstract: The need for variations in learning resources for students of SMK Diponegoro Tumpang and the development of $2^{\text {st }}$ century technology are the basis of this development research. The purpose of this paper is to describe the development of valid, practical and effective learning media for combinatoric material. This development uses the ADDIE model. The test subjects in the development of learning media consisted of expert validators, practitioner validators, observers, 5 students of class XII as group trials, and 22 students of class XII KPR as field trials. The instruments used were learning media, lesson plans, observation sheets, student response questionnaires, and teacher response questionnaires. The results of the development state that learning media are valid, practical, and very effective.

\begin{abstract}
Abstrak: Kebutuhan variasi sumber belajar bagi siswa SMK Diponegoro Tumpang dan perkembangan teknologi abad 21 merupakan dasar dari penelitian pengembangan ini. Tujuan penulisan ini adalah mendeskripsikan pengembangan media pembelajaran materi kombinatorika yang valid, praktis, dan efektif. Pengembangan ini menggunakan model ADDIE. Subjek uji coba dalam pengembangan media pembelajaran ini terdiri dari validator ahli, validator praktisi, observer, 5 siswa kelas XII sebagai uji coba kelompok, dan 22 siswa kelas XII KPR sebagai uji coba lapangan. Instrumen yang digunakan adalah media pembelajaran, RPP, lembar observasi, angket respon siswa, dan angket respon guru. Hasil pengembangan menyatakan bahwa media pembelajaran valid, praktis, dan sangat efektif.
\end{abstract}

\author{
Alamat Korespondensi: \\ Ana Cholila \\ Pendidikan Matematika \\ Universitas Negeri Malang \\ Jalan Semarang 5 Malang \\ E-mail: a_cholila@yahoo.co.id
}

Kebutuhan variasi sumber belajar bagi siswa SMK Diponegoro Tumpang merupakan dasar dari penilitian pengembangan ini. Hal ini didukung oleh observasi di SMK Diponegoro Tumpang bahwa terdapat beberapa permasalahan yang ditemukan dalam pembelajaran matematika, di antaranya (1) model pembelajaran yang masih terpusat pada guru sehingga menyebabkan pembelajaran kurang bermakna karena siswa tergantung pada informasi yang disampaikan oleh guru, (2) media yang digunakan masih terpusat pada buku teks. Buku teks merupakan media pembelajaran yang sudah terbiasa digunakan oleh guru, seperti buku paket, modul, dan LKS. Menurut (Suastika, 2017) yang menyatakan bahwa pembelajaran Matematika pada sekolah menengah masih konvensional dimana guru masih masih mendominasi kegiatan pembelajaran sehingga siswa tidak mampu mengembangkan kreativitasnya. Informasi yang diperoleh selanjutnya adalah masih belum ada media interaktif berupa animasi dalam pembelajaran Matematika. Hal ini dikarenakan keterbatasan waktu dan kemampuan untuk membuat media pembelajaran. Oleh karena itu, diperlukan pengembangan media pembelajaran yang memanfaatkan kemajuan teknologi dan komunikasi. Menurut (Yoong, 2016) kemajuan teknologi merupakan komponen pada pendidikan abad 21. Zubaidah (2016) menyatakan pada perkembangan abad 21 diharapkan guru mampu menyediakan sumber belajar yang sesuai dengan kemampuan siswa melalui media pembelajaran. Oleh karena itu, dibutuhkan variasi sumber belajar yang lain yang valid, praktis, dan efisien yang mampu dimanfaatkan siswa dimanapun dan kapanpun.

Media pembelajaran yang dikembangkan diharapkan mampu membuat siswa belajar secara mandiri. Menurut (Zaranis, 2016) pembelajaran menggunakan teknologi berbantuan komputer mampu memberikan efek positif bagi siswa dan lebih efektif dalam kegiatan pembelajaran. Menurut (Dwiyantiningrum, 2016) kebutuhan media pembelajaran berbasis media flash bertujuan untuk meningkatkan minat belajar siswa, membuat siswa mampu belajar secara mandiri dan menfasilitasi ketidakmampuan siswa dalam memahami materi pelajaran. Menurut (Wibowo, 2013) media pembelajaran digunakan untuk mengenalkan materi pembelajaran yang sulit untuk dipahami siswa dalam bentuk tulisan sehingga dibutuhkan tampilan yang menarik berupa gabungan visualisasi gambar dan animasi. Oleh karena itu, pengembangan media pembelajaran diharapkan mampu memberikan variasi sumber belajar bagi siswa dan meningkatkan motivasi dalam pembelajaran matematika. 
Pembelajaran matematika berbasis media interaktif bertujuan memberikan pengalaman belajar yang berkesan bagi siswa. Menurut (Kissane, 2014) pembelajaran Matematika berbasis media mampu memberikan pengalaman belajar yang baru bagi siswa. Pembelajaran matematika berbasis media memfokuskan pada membuat materi pembelajaran lebih bermakna sehingga mampu membuat siswa mampu memahami konsep materi matematika dengan baik. Selain itu, diharapkan siswa memiliki kepekaan dalam membuat koneksi dan mengaplikasikan matematika dalam kehidupan nyata. (Jabbour, 2012) menyatakan bahwa pembelajaran berbasis multimedia memiliki daya tarik bagi siswa untuk terlibat aktif dalam memahami materi yang disajikan. Hal ini dikarenakan media pembelajaran terdiri dari multimedia yang mengombinasikan kata-kata, grafik, suara, dan animasi. Lebih lanjut, (Jabbour, 2012) menyatakan bahwa hendaknya guru menyesuaikan kebutuhan siswa dalam penggunaan multimedia dalam pembelajaran. Kebutuhan tersebut meliputi pengetahuan awal siswa, tingkat pemahaman siswa dan tujuan dari pembelajaran. Oleh karena itu, dalam pembuatan media pembelajaran matematika harus menyesuaikan kebutuhan siswa agar pembelajaran menjadi lebih bermakna dan tujuan pembelajaran tercapai.

Berdasarkan uraian di atas, maka peneliti mengembangkan media pembelajaran materi kombinatorika. Pengembangan media pembelajaran ini bertujuan untuk mendeskripsikan hasil pengembangan media pembelajaran kombinatorika yang valid, praktis dan efektif.

\section{METODE}

Penelitian pengembangan ini mengguanakan model ADDIE yang dikembangkan oleh (Lee \& Owens, 2004). Tahaptahap pengembangan ini terdiri dari (1) analysis (analisis), (2) design (perancangan), (3) development (pengembangan), (4) implementation (implementasi), dan (5) evaluation (evaluasi).

Pada penelitian pengembangan ini dilakukan desain uji coba produk, meliputi uji kevalidan, uji kepraktisan, dan uji keefektifan. Uji kevalidan diperoleh dari hasil validasi instrumen oleh validator ahli materi dan media. Instrumen penelitian yang digunakan berupa media pembelajaran, RPP, lembar observasi, angket respon guru, dan angket respon siswa. Subjek uji coba dalam evaluasi produk pengembangan media pembelajaran berbasis media interaktif materi kombinatorika terdiri dari validator ahli, validator praktisi, observer, uji coba kelompok pada lima siswa SMK Diponegoro Tumpang kelas XII yang dipilih secara acak, dan uji coba lapangan pada 22 siswa SMK Diponegoro Tumpang kelas XII KPR.

Teknik analisis data dalam penelitian pengembangan ini, meliputi (1) hasil uji kevalidan, (2) hasil uji kepraktisan, dan (3) hasil uji keefektifan. Berikut disajikan rumus untuk menghitung hasil rata-sata kevalidan media pembelajaran dan menentukan hasil rata-rata kepraktisan media pembelajaran, dilakukan perhitungan yang akan ditunjukkan pada rumus berikut. Untuk menentukan kriteria tingkat kevalidan dan kepraktisan media pembelajaran ditunjukkan pada tabel 1.

$$
N=\frac{\sum_{i=1}^{m} X_{i}}{m}
$$

$N$ merupakan Rataan total nilai validasi dari seluruh validator untuk seluruh indikator. $X i$ merupakan rataan nilai hasil validasi dari semua validator untuk setiap indikator ke-i. $m$ : Banyaknya indikator.

Tabel 1. Kriteria Tingkat Kevalidan dan Kepraktisan Media Pembelajaran

\begin{tabular}{lll}
\hline Nilai $\boldsymbol{N}$ & Tingkat Kevalidan & Tingkat Kepraktisan \\
\hline$N=3$ & Sangat Valid & Sangat Praktis \\
$2 \leq N<3$ & Valid & Praktis \\
$1 \leq N<2$ & Kurang Valid & Kurang Praktis \\
$0 \leq N<1$ & Tidak Valid & Tidak Praktis \\
\hline
\end{tabular}

Sumber: (Suwarno, 2017)

Untuk mengetahui tingkat keefektifan, digunakan perhitungan dengan persentase siswa yang memperoleh nilai di atas SKM, yaitu nilai 75. Persentase siswa yang mendapat nilai di atas KKM dihitung dengan rumus berikut yang diadopsi dari (Suwarno, 2017).

$$
E=\frac{x}{n} \times 100 \%
$$

E merupakan presentase siswa yang mendapat nilai di atas SKM. $x$ merupakan banyaknya siswa yang mendapat nilai di atas SKM. $n$ merupakan banyaknya siswa uji coba. Untuk mengetahui kriteria tingkat keefektifan media pembelaharan, akan dijelaskan pada tabel 2. 
Tabel 2. Kriteria Uji Keefektifan Media Pembelajaran

\begin{tabular}{cl}
\hline \multicolumn{1}{c}{ Nilai $\boldsymbol{E}$} & Tingkat Keefektifan \\
\hline $\mathbf{8 0} \% \leq \boldsymbol{E} \leq \mathbf{1 0 0} \%$ & Sangat Efektif \\
$\mathbf{6 0} \% \leq \boldsymbol{E}<\mathbf{8 0} \%$ & Efektif \\
$\mathbf{4 0} \% \leq \boldsymbol{E}<\mathbf{6 0} \%$ & Cukup Efektif \\
$\mathbf{2 0} \% \leq \boldsymbol{E}<\mathbf{4 0} \%$ & Kurang Efektif \\
$\mathbf{0} \% \leq \boldsymbol{E}<\mathbf{2 0} \%$ & Tidak Efektif \\
\hline
\end{tabular}

(Sumber: Suwarno, 2017)

Jenis data pada penelitian pengembangan ini berupa data kualitatif dan kuantitatif. Data kualitatif berupa komentar dan komentar yang diberikan oleh validator, observer, siswa, dan guru. Data kuantitatif diperoleh dari skor penilaian terhadap instrumen penelitian pengembangan ini.

\section{HASIL}

Hasil pengembangan ini berupa media pembelajaran berbasis media interaktif materi kombinatorika untuk siswa SMK. Media pembelajaran ini dapat digunakan pada komputer atau laptop dengan spesifikasi windows 8 maupun windows 10 . Berikut tampilan media pembelajaran berbasis media interaktif pada materi kombinatorika yang telah dibuat. Tampilan pada gambar 1 merupakan tampilan awal media pembelajaran kombinatorika saat siswa membuka media pembelajaran. Tampilan pada gambar 2 merupakan tampilan pembuka yang memberikan gambaran secara umumm tentang media pembelajaran. Pada tampilan tersebut terdapat link untuk membuka petunjuk penggunaan media pembelajaran. Tampilan gambar 3 merupakan tampilan beranda utama pada media pembelajaran yang berisi beberapa menu, di antaranya kompetensi, materi, latihan soal, evaluasi, bantuan (petunjuk penggunaan media), dan sumber (yang berisi info pengembang dan daftar pustaka).

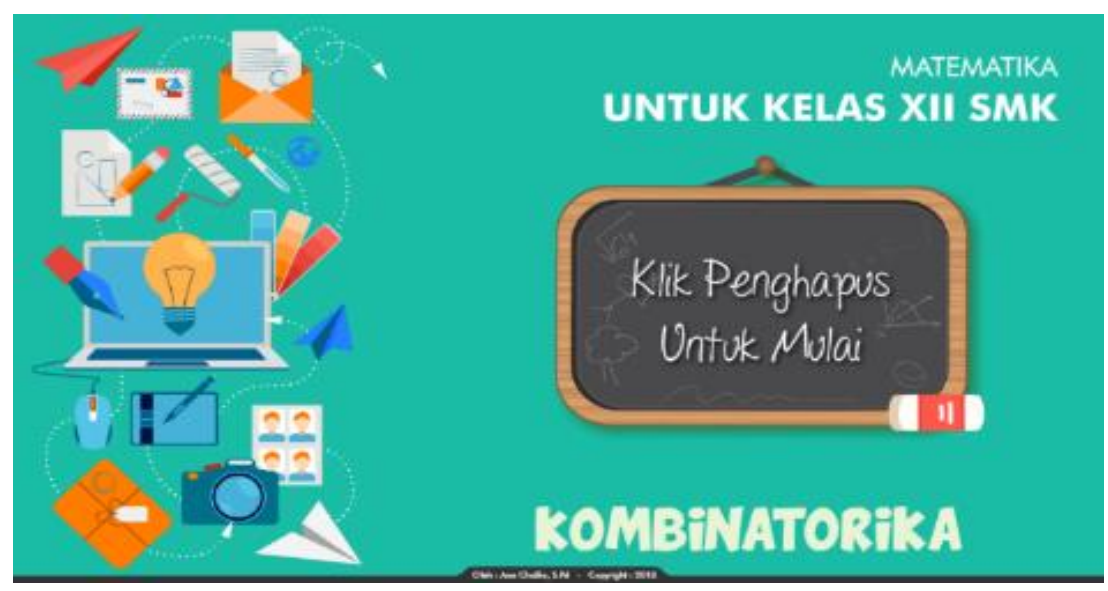

Gambar 1. Tampilan Awal Media Pembelajaran

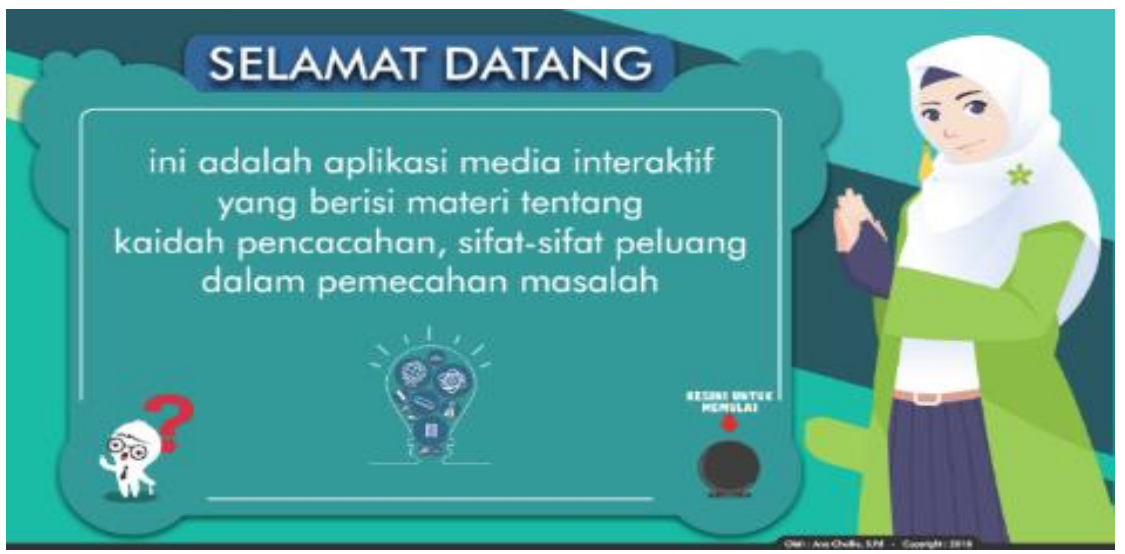

Gambar 2. Tampilan Info Mengenai Aplikasi Media Pembelajaran 


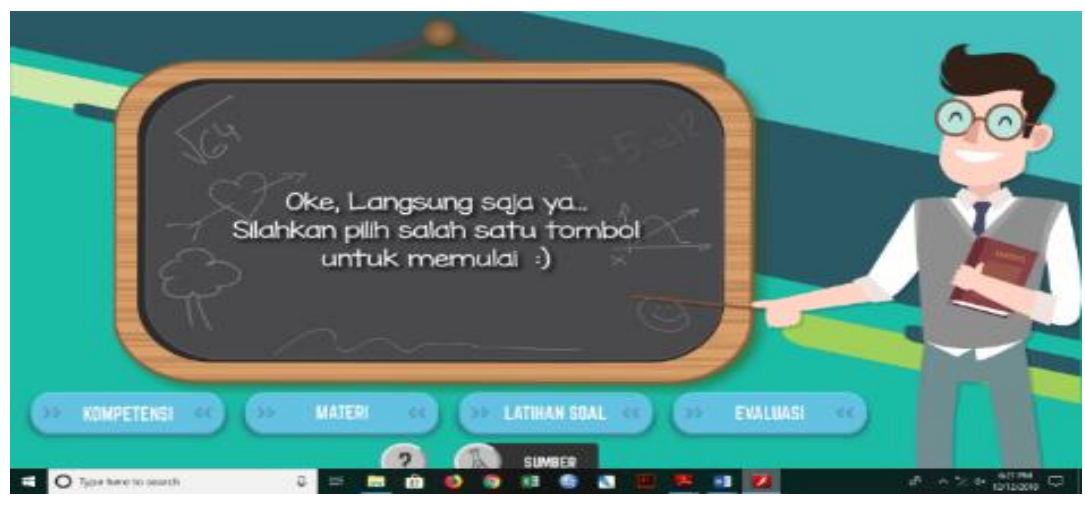

Gambar 3. Tampilan Beranda Utama

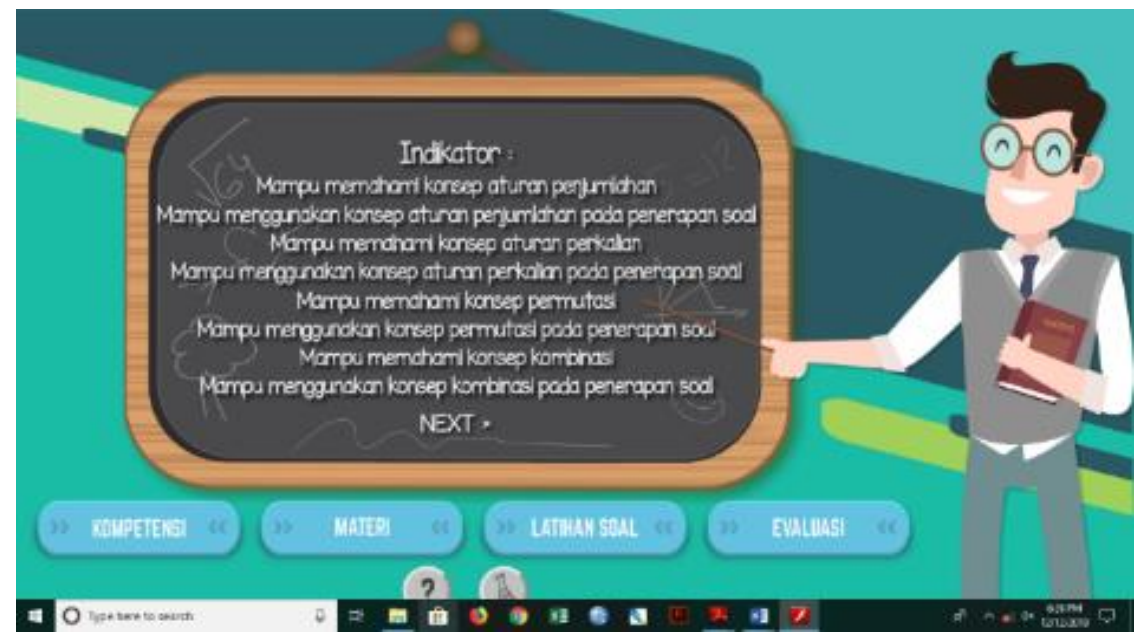

Gambar 4. Tampilan Kompetensi, Indikator, dan Tujuan Pembelajaran

Tampilan pada gambar 4 berisi tentang kompetensi, indikator dan tujuan pembelajaran. Tampilan pada gambar 5 merupakan tampilan materi yang akan disajikan pada media pembelajaran. Pada tampilan tersebut terdiri dari dua menu pilihan yang dapat dipilih siswa. Tampilan gambar 6 merupakan tampilan materi pada media pembelajaran yang menggunakan klik and drag yang bertujuan agar siswa mampu menentukan penyelesaian penyusunan bendera dengan memilih warna yang siswa sukai. Tampilan gambar 7 merupakan tampilan latihan soal yang terdiri dari tiga menu pilihan sesuai dengan materi yang telah disajikan pada media pembelajaran. Pada latihan soal terdapat soal pilihan ganda, respon hasil yang diperoleh siswa berupa nilai yang diperoleh beserta pembahasan.

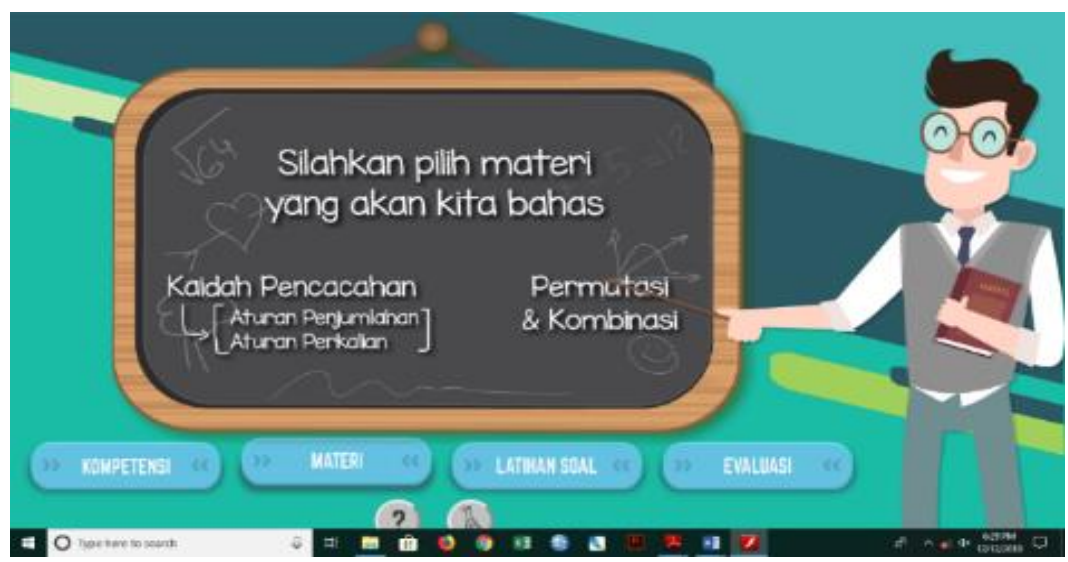

Gambar 5. Tampilan Materi 


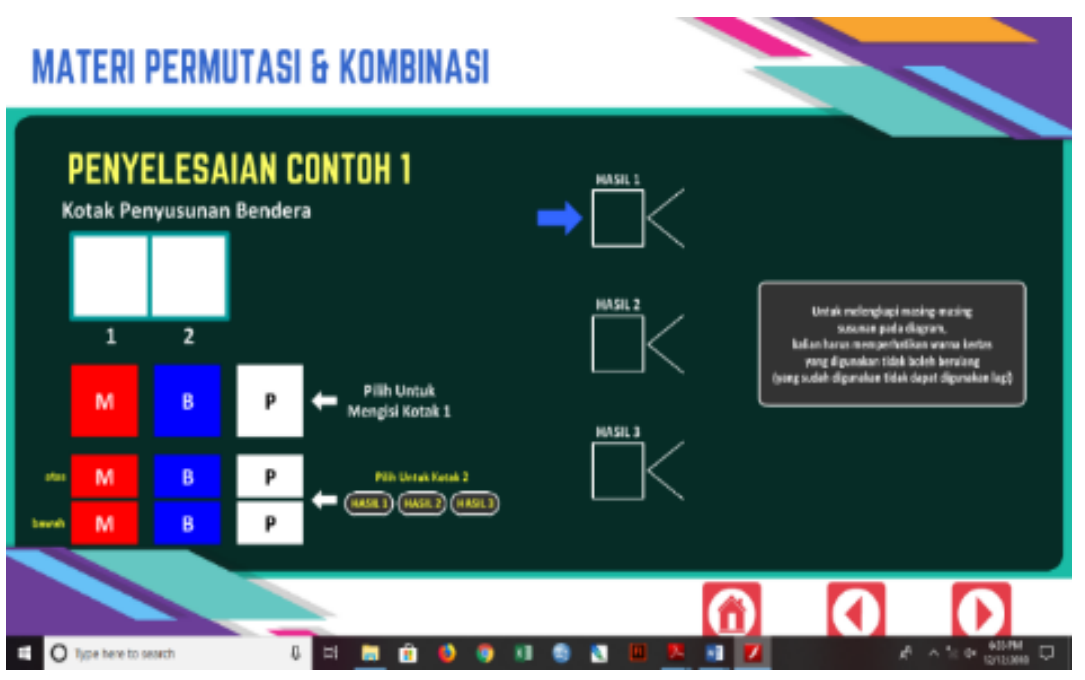

Gambar 6. Tampilan Materi Menggunakan Klik dan Drag

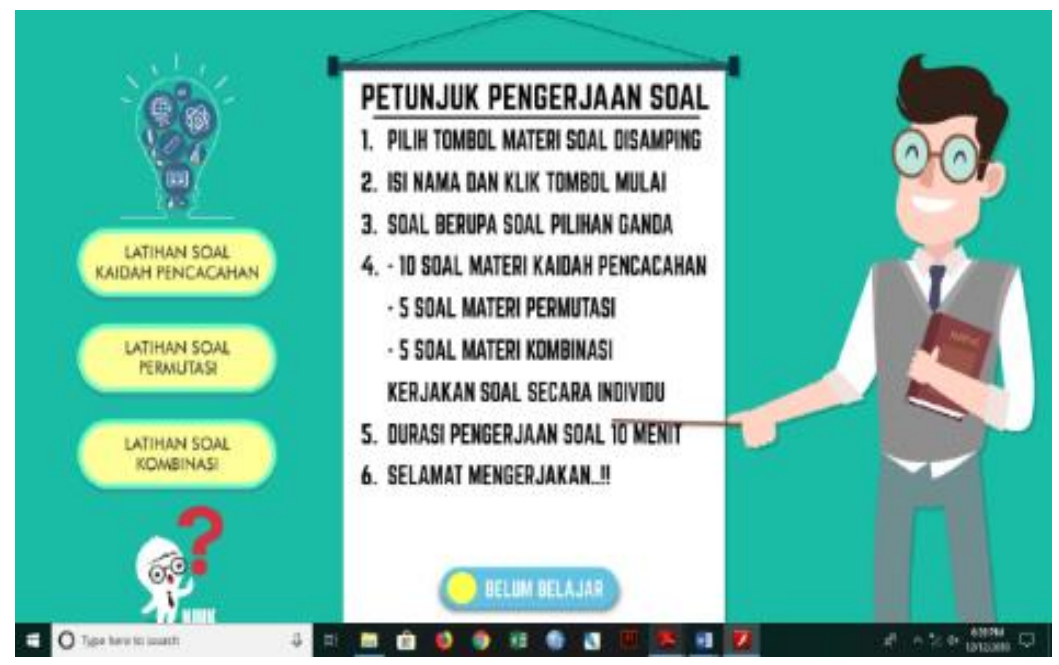

Gambar 7. Tampilan Latihan Soal

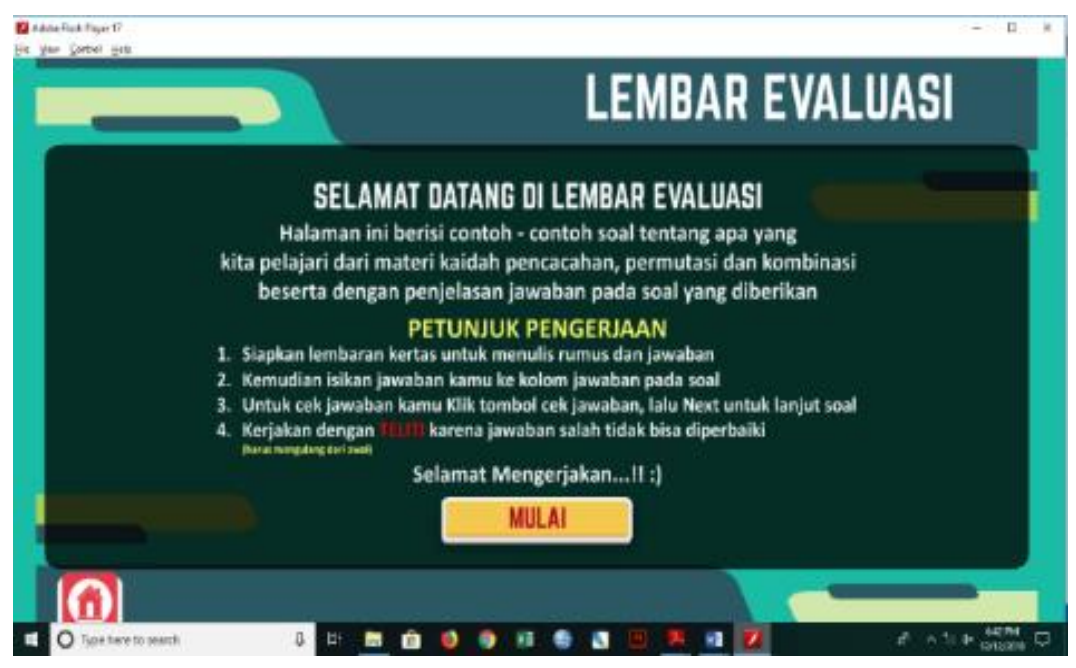

Gambar 8. Tampilan Petunjuk Pengisian Lembar Evaluasi 


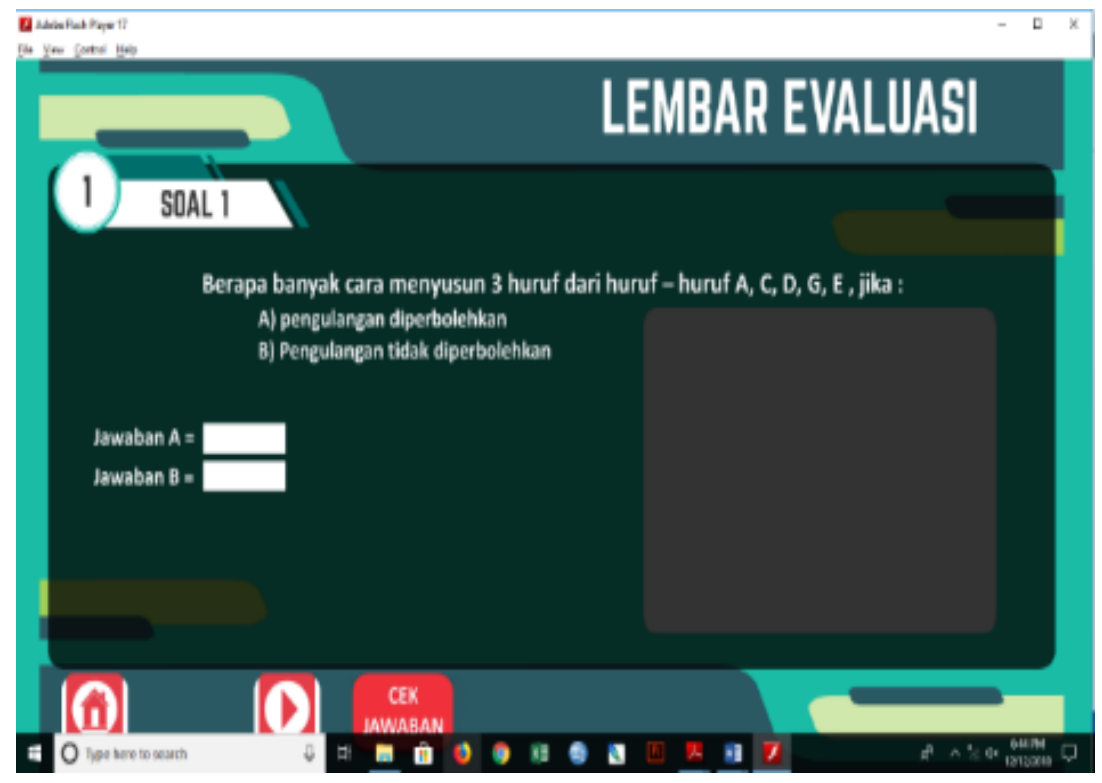

Gambar 9. Tampilan Lembar Evaluasi

Tampilan gambar 8 merupakan tampilan yang berisi petunjuk dalam pengisian lembar evaluasi agar siswa dapat menyelesaiakn setiap soal dengan teliti dan benar. Pada gambar 9 merupakan tampilan lembar evaluasi. Lembar evaluasi didesain dengan pengisian singkat melalui computer sehingga siswa lebih efisien dan praktis.

Berdasakan hasil dari uji kevalidan, diperoleh hasil validasi media, RPP, lembar observasi, lembar angket respon siswa, dan lembar angket respon guru. Dari hasil analisis data terhadap validasi media oleh dua validator diperoleh rataan total nilai hasil validasi dari kedua validator untuk keseluruhan indikator adalah 2,72. Berdasarkan rata-rata total nilai hasil validasi diperoleh kriteria bahwa media pembelajaran berbasis media interaktif materi kombinatorika untuk siswa SMK dinyatakan "valid". Hasil analisis data terhadap validasi RPP yang diperoleh dari dua validator diperoleh rata-rata hasil validasi seluruh indikator sebesar 2,6. Berdasarkan hasil validasi yang diperoleh, maka RPP yang akan digunakan memperoleh kriteria "valid". Data analisis hasil validasi lembar observasi keterlaksanaan media pembelajaran diperoleh nilai rata-rata total semua indikator sebesar 2,86 dan mendapat kriteria "valid". Hasil validasi angket respon guru oleh dua validator diperoleh nilai rata-rata keseluruhan indikator sebesar 2,83 dan memperoleh kriteria "valid". Hasil validasi angket respon siswa oleh dua validator diperoleh nilai rata-rata keseluruhan indikator sebesar 2,83 dan memperoleh kriteria "valid".

Hasil uji kepraktisan diperoleh respon dari lembar observasi, angket respon guru dan angket respon siswa. Hasil observasi yang diperoleh dari uji coba lapangan yaitu sebesar 2,6 dan dinyatakan "praktis". Hasil keseluruhan analisis angket respon guru matematika yang mendampingi pembelajaran subjek uji coba lapangan diperoleh rata-rata skor indikator sebesar 2,48. Berdasarkan rata-rata skor yang diberikan, media dinyatakan memperoleh kriteria "praktis". Hasil penilaian terhadap keseluruhan aspek pada angket respon siswa adalah sebesar 2,35. Hal ini menunjukkan bahwa media pembelajaran berbasis media interaktif materi kombinatorika dinyatakan "praktis". Berdasarkan hasil uji kepraktisan tersebut, maka media pembelajaran materi kombinatorika dinyatakan praktis. Hasil uji keefektifan ditunjukkan dengan persentase siswa yang memperoleh nilai uji kompetensi di atas KKM (Kriteria Ketuntasan Minimal) sebesar 86\%. Hal ini menunjukkan bahwa tingkat keefektifan produk memperoleh kriteria "Sangat Efektif'.

\section{PEMBAHASAN}

Media pembelajaran berbasis media interaktif materi kombinatorika yang telah dikembangakan dapat digunakan oleh siswa SMK Diponegoro Tumpang sebagai referensi sumber belajar sesuai perkembangan teknologi pembelajaran abad 21. Hal ini sesuai dengan pendapat Zubaidah (2016), Yoong (2016), dan (Martin \& Carr, 2015). (Zubaidah, 2016) yang menyatakan pada perkembangan abad 21 bahwa guru hendaknya mampu menyediakan referensi belajar bagi siswa berupa media pembelajaran. (Yoong, 2016) menyatakan bahwa kemajuan teknologi merupakan komponen pada pendidikan abad 21. (Martin \& Carr, 2015) menyatakan bahwa dalam pembelajaran matematika pada grade 12 sebaiknya guru menggunakan teknologi multimedia dalam pembelajaran utuk memenuhi tantangan pembelajaran abad 21 .

Media pembelajaran berbasis media interaktif materi kombinatorika tidak hanya menampilkan materi berupa tulisan tetapi juga animasi dan input bagi siswa untuk menuliskan respon jawaban terhadap pertanyaan yang diberikan kepada siswa. Input jawaban tersebut diberikan pada konten materi bertujuan untuk memberikan pengalaman belajar yang bermakna bagi siswa sehingga siswa memahami setiap proses dalam pembelajaran materi yang diajarkan. Hal ini sesuai dengan pendapat (Kissane, 2014) yang menyatakan bahwa pembelajaran berbasis media mampu memberikan pengalaman belajar yang baru bagi 
siswa. Pada media pembelajaran kombinatorika ditampilkan animasi untuk memudahkan siswa memahami materi permutasi dan kombinasi. Hal ini sesuai dengan pendapat (Wibowo, 2013) media pembelajaran digunakan untuk mengenalkan materi pembelajaran yang sulit untuk direpresentasikan dalam bentuk tulisan sehingga dibutuhkan tampilan yang menarik berupa gabungan gambar dan animasi.

Berdasarkan hasil uji coba media pembelajaran, menunjukkan bahwa media pembelajaran berbasis media interaktif materi kombinatorika telah memperoleh kriteria yang valid, praktis, dan efektif. Media pembelajaran materi kombinatorika merupakan solusi untuk menangani ketidakmampuan siswa dalam memahami materi dalam bentuk buku teks. Hal ini sesuai dengan pendapat (Fahmi \& Marsigit, 2014) bahwa dalam membantu siswa agar lebih memahami materi dibutuhkan macromedia flash yang merupakan software pembuat animasi interaktif. Melalui pengembangan media pembelajaran kombinatorika, guru dapat mengatur waktu kegiatan pembelajaran secara efektif. Hal ini sesuai dengan pendapat (Dwiyantiningrum, 2016) yang keberadaan media pembelajaran meminimalkan jumlah jam mengajar dan mampu meningkatkan kualitas belajar siswa.

Berdasarkan hasil uji keefektifan yang dilakukan pada akhir pembelajaran diperoleh hasil bahwa kriteria siswa yang memeperoleh nilai di atas KKM adalah 86\%. Hal ini sesuai dengan pendapat (Riyanto \& Gunarhadi, 2017) siswa yang melakukan pembelajaran matematika menggunakan multimedia interaktif dapat meningkatkan hasil pembelajaran berupa peningkatan nilai siswa. (Anjarwati, Winarno, \& Churiyah, 2016) juga menyatakan bahwa melalui pembelajaran mengunakan media flash mampu meningkatkan hasil belajar siswa dan pemahaman siswa. (Joan \& Denisa, 2012) menyatakan bahwa pembelajaran menggunakan multimedia mampu meningkatkan keefektifan dalam peningkatan hasil belajar siswa yang memiliki kemampuan rendah.

\section{SIMPULAN}

Berdasarkan hasil pengembangan media pembelajaran berbasis media interaktif materi kombinatorika diperoleh hasil sebagai berikut. Hasil validasi media pembelajaran oleh ahli materi dan media menunjukkan kriteria bahwa media pembelajaran berbasis media interaktif materi kombinatorika untuk kelas XII SMK dinyatakan "valid". Kevalidan ditunjukkan oleh kesesuaian aspek pada instrumen penelitian dengan lembar validasi. Hasil analisis dalam uji kepraktisan diperoleh dari lembar observasi, angket respon guru, dan angket respon siswa. Berdasarkan hasil analisis pada instrumen kepraktisan menunjukkan bahwa media pembelajaran berbasis media interaktif materi kombinatorika dinyatakan memperoleh kriteria "praktis". Untuk mengetahui uji keefektifan, dilakukan uji komoetensi. Berdasarkan hasil analisis yang diperoleh, presentase siswa yang mendapatkan nilai di atas KKM (Kriteria Kelulusan Minimal) menunjukkan bahwa tingkat keefektifan produk memperoleh kriteria "Sangat Efektif".

Pada pengembangan media, pembelajaran ini terdapat kelebihan, salah satunya media pembelajaran memuat materi kombinatorika, media dikemas dalam bentuk.apk sehingga memudahkan siswa untuk menggunakannya di luar jam pelajaran di sekolah, dan kemudahan dalam penggunaannya. Selain terdapat kelebihan, media ini juga memiliki kekurangan, yaitu materi yang ditampilkan masih membutuhkan penyempurnaan untuk menambah pengetahuan siswa. Dalam rangka mengoptimalkan pemanfaatan media pembelajaran materi kombinatorika, pengembang memberikan saran-saran sebagai berikut. Pertama, media pembelajaran ini dapat digunakan sebagai sumber referensi lain dalam pembelajaran materi peluang. Kedua, sehubungan dengan keterbatasan dalam konten materi media pembelajaran, hendaknya guru dalam memanfaatkan media pembelajaran menggunakan sumber referensi lain untuk penunjang dalam pembelajaran.

Pada pengembangan media pembelajaran berbasis media interaktif materi kombinatorika, pengembang hanya menyebarkan media pembelajaran berbasis aplikasi android yang memiliki format apk hanya pada siswa kelas XII SMK Diponegoro Tumpang. Apabila digunakan pada siswa sekolah yang lain, perlu pertimbangan bahwa media pembelajaran dapat disebarluaskan melalui software share it pada aplikasi ponsel. Saran pengembangan media pembelajaran lebih lanjut, yaitu (1) media pembelajaran berbasis media interaktif materi kombinatorika perlu dikembangkan dan dimodifikasi secara terus-menerus dalam segi tampilan dan animasi untuk memperoleh produk yang lebih sempurna dan mengikuti perkembangan teknologi sehingga dapat menambah motivasi siswa dalam penggunaannya (2) konten isi perlu dikembangkan secara terus-menerus mengikuti perkembangan zaman.

\section{DAFTAR RUJUKAN}

Anjarwati, D., Winarno, A., \& Churiyah, M. (2016). Improving Learning Outcomes by Developing Instructional Media-Based Adobe Flash Professional CS 5 . 5 on Principles of Business Subject. IOSR Journal of Research \& Method in Education, 6(5), 1-6. https://doi.org/10.9790/7388-0605010106

Dwiyantiningrum, I. (2016). Pengembangan Bahan Ajar Kompetensi Mengelola Dana Kas Kecil Berbasis Media Flash pada Siswa SMK Bisnis dan Manajemen. Tesis tidak diterbitkan. Universitas Negeri Malang, Malang.

Fahmi, S., \& Marsigit. (2014). Pengembangan Multimedia Macromedia Flash dengan Pendekatan Kontekstual dan

Keefektifannya terhadap Sikap Siswa pada Matematika. Phytagoras: Jurnal Pendidikan Matematika, 9(1), 90-98.

Jabbour, K. K. (2012). Multimedia Principle in Teaching Lessons. Acta Didactica Napocensia, 5(4), 11-16.

Joan, D. R. R., \& Denisa, S. (2012). Multimedia Approach and its Effect in Teaching Mathematics for the Prospective Teachers. I-Manager's Journal on School Educational Technology, 8(2), 44-49. 
Lee, W. W., \& Owens, D. L. (2004). Multimedia-Based Instructional Design (Second). San Fransisco: Pfeiffer.

Martin, F., \& Carr, M. L. (2015). An Exploratory Study on K-12 Tearchers' Use of Technology and Multimedia in the Classroom. I-Manager's Journal of Education Technology, 12(1), 7-14.

Riyanto, W. D., \& Gunarhadi. (2017). The Effectiveness of Interactive Multimedia in Mathematic Learning: Utilizing Power Points for Students with Learning Disability. International Journal of Pedagogy and Teacher Education, 1(1), 55-63. https://doi.org/10.20961/ijpte.v1i1.8400

Suastika, K. (2017). Mathematics Learning Model of Open Problem Solving to Develop Students' Creativity. IEJME Mathematics Education, 12(6), 569 - 577.

Suwarno, M. (2017). Pengembangan Multimedia Pembelajaran Matematika Berbantuan Komputer Berbasis Video Lectures pada Materi Trigonometri II untuk Siswa Kelas XI SMK. Tesis tidak diterbitkan. Universitas Negeri Malang, Malang.

Wibowo, E. J. (2013). Media Pembelajaran Interaktif Matematika untuk Siswa Sekolah Dasar Kelas IV. Seminar Riset Unggulan Nasional Informatika dan Komputer FTI UNSA, 2(1), 75-78.

Yoong, W. K. (2016). Developing $21^{\text {st }}$ Century Competencies in the Mathematics Classroom: Enriching Secondary Mathematics Education with $21^{\text {st }}$ Century Competencies: 33 - 50. Singapore: World Scientific.

Zaranis, N. (2016). The use of ICT in Kindergarten for Teaching Addition Based on Realistic Mathematics Education. Education and Information Technologies, 21(3), 589-606. https://doi.org/10.1007/s10639-014-9342-8

Zubaidah, S. (2016). Keterampilan Abad ke-21: Keterampilan yang diajarkan melalui Pembelajaran. Seminar Nasional Pendidikan Prodi Biologi STIKP Persada Khatulistiwa Sintang-Kalimantan Barat. Desember: 1 - 17. 